\title{
Entrevista de Crianças e Adolescentes em Contexto Policial e Forense: Uma Perspectiva do Desenvolvimento
}

\author{
Investigative Interviewing of Children and Adolescents: \\ A Developmental Perspective
}

\author{
Rui Paulo*, ${ }^{*}$, Pedro B. Albuquerque ${ }^{a} \&$ Ray Bull ${ }^{b}$ \\ ${ }^{a}$ Universidade do Minho, Braga, Portugal \& ${ }^{b}$ University of Portsmouth, Portsmouth, Reino Unido
}

\begin{abstract}
Resumo
Conhecer as diferentes etapas do desenvolvimento humano é uma competência essencial para o entrevistador em contexto policial e forense. É imprescindível adaptar a entrevista em função da avaliação das competências da testemunha. Este artigo caracteriza as etapas do desenvolvimento humano ao longo da infância e adolescência, destacando o desenvolvimento da memória e outras competências relevantes para a entrevista de testemunhas. Analisou-se ainda a adequabilidade de várias metodologias utilizadas para este fim, salientando algumas diretrizes fundamentais para a condução de uma boa entrevista. Por fim, focou-se na Entrevista Cognitiva Melhorada enquanto técnica promissora para entrevistar crianças e adolescentes. Pretende-se não apenas rever de forma crítica a literatura existente, mas também construir um guia para os profissionais desta área.

Palavras-chave: Entrevista cognitiva, entrevista investigativa, desenvolvimento humano, crianças, adolescentes.
\end{abstract}

\begin{abstract}
Knowing the different developmental stages is an essential skill for the forensic or police interviewer. It is crucial to adapt the interview according to the witness developmental assessment. This article describes the stages of human development throughout childhood and adolescence, with particular emphasis on the development of memory and other skills involved in the interview process. The appropriateness of several methodologies used for interviewing child witnesses is discussed, as well as some fundamental guidelines for conducting a good interview. Lastly, the article focuses on the Enhanced Cognitive Interview as a promising technique for interviewing children and adolescents. The aim of this study is not only to critically review the existing studies, but also to write a guide for professionals in this area.

Keywords: Cognitive interview, investigative interview, human development, children, adolescent.
\end{abstract}

Conhecer as principais características das diversas etapas do desenvolvimento humano é uma competência essencial não só para um psicólogo que trabalhe em contexto clínico, forense ou escolar, mas também para outros profissionais que necessitam de lidar e/ou avaliar crianças e adolescentes (Saywitz \& Camparo, 1998). No contexto criminal e forense, que enfocaremos ao longo deste artigo, o psicólogo, tal como o detetive policial, precisa também conhecer e dominar estes aspectos, por exemplo, para entrevistar crianças de forma adequada (Lamb, La Rooy,

" Endereço para correspondência: Universidade do Minho, Escola de Psicologia, Centro de Investigação em Psicologia, Campus de Gualtar, Gualtar, Braga, Portugal 4710-057. E-mail: id4299@alunos.uminho. pt, pedro.b.albuquerque@psi.uminho.pt e ray.h.bull@ btinternet.com

Agradecemos à Professora Carla Martins pelo auxilio prestado na realização deste artigo.

Este trabalho foi financiado pela "Fundação para a Ciência e a Tecnologia" de Portugal (Referência: SFRH / BD / 84817/2012).
Malloy, \& Katz, 2011). De fato, diversas vezes um detetive policial se encontra perante situações em que uma criança foi testemunha de um crime. Por vezes, não só é a única testemunha, mas a própria vítima do crime, particularmente em casos de negligência ou abuso parental. No entanto, o conhecimento que estes profissionais possuem acerca do desenvolvimento humano nem sempre provém de evidência científica, mas sim de representações sociais e culturais que podem não ser fidedignas (Almeida \& Cunha, 2003).

Existe a crença de que a criança é incapaz de produzir um bom testemunho, em grande medida por questões relacionadas com a sugestionabilidade, ou seja, o grau em que a codificação, armazenamento, recuperação e evocação de um evento pode ser influenciado por fatores internos e externos. No entanto, a investigação tem mostrado precisamente o contrário (Brainerd \& Reyna, 2012). Hershkowitz, Lamb, Orbach, Katz, e Horowitz (2012) concluem que uma criança com mais de três anos de idade pode já ser capaz de prestar um bom relato. No entanto, a qualidade do testemunho obtido depende, em parte, das 
competências e treino do entrevistador, bem como do conhecimento que este possui acerca das potencialidades e limitações da criança (Poole \& Lamb, 1998). Assim, avaliar o funcionamento cognitivo, emocional e social da criança, associado à sua fase desenvolvimental, é um processo essencial (Toeplitz-Winiewska, 2007).

Nesta revisão não sistemática da literatura, o foco será a importância que o conhecimento de conceitos básicos e da trajetória normativa do desenvolvimento humano tem na condução de entrevistas direcionadas a testemunhas. Isto porque, durante as investigações policiais e forenses, a entrevista de testemunhas é frequentemente um procedimento que determina o sucesso da investigação (Dando, Wilcock, Milne, \& Henry, 2008). Serão descritas as várias etapas do desenvolvimento humano, salientando o desenvolvimento da memória, bem como as diretrizes a seguir para cada etapa de desenvolvimento, na construção e condução de uma entrevista adequada. Serão também abordados aspectos gerais importantes a considerar na condução de entrevistas a crianças e adolescentes. Por fim, focaremos a Entrevista Cognitiva Melhorada (Fisher \& Geiselman, 1992), um dos modelos de entrevista mais estudado e utilizado no mundo, com comprovada eficácia com adultos, crianças e adolescentes (Gentle, Milne, Powell, \& Sharman, 2013).

\section{Desenvolvimento da Criança e do(a) Adolescente}

O desenvolvimento humano envolve uma sequência de transformações sucessivas e reorganizações comportamentais contínuas, sendo influenciado por diversos fatores. Estes factores (e.g., genéticos e ambientais), condicionam o funcionamento do indivíduo ao nível físico, cognitivo, emocional e/ou social (Papalia, Olds, \& Feldman, 2009). Assim, crianças da mesma idade poderão apresentar percursos desenvolvimentais ligeiramente diferentes (Martin $\&$ Fabes, 2009). Por exemplo, o desenvolvimento cognitivo pode ser diferente em crianças nascidas a termo e crianças nascidas pré-termo, com as últimas a apresentarem mais frequentemente um nível intelectual inferior à média e problemas comportamentais (Linhares, Chimello, Bordin, Carvalho, \& Martinez, 2005). Variáveis como o rendimento da família e a escolaridade materna também afetam o desenvolvimento. Crianças inseridas em famílias com maior rendimento, bem como crianças cujas mães possuem elevado grau de escolaridade, apresentam um maior índice de desenvolvimento mental (Lordelo, Chalhub, Guirra, \& Carvalho, 2007). Não obstante estes factores que explicam as diferenças individuais no desenvolvimento de cada criança, é possível identificar características típicas de cada faixa etária, e assim delimitar diversas fases de desenvolvimento: o período pré-natal; o período neonatal que corresponde aos primeiros 28 dias de vida; a primeira infância que vai até o aparecimento da linguagem; a segunda infância, que compreende o período pré-escolar e escolar; a adolescência; e, por fim, a idade adulta. Esta pode ser dividida em diversas fases, e se inicia quando o indivíduo se torna maior de idade (Dehart, Sroufe, \& Cooper, 2004). Neste artigo, a ênfase será, essencialmente, na primeira infância, segunda infância e adolescência.

\section{Primeira Infância}

O recém-nascido possui um conjunto de competências sensório-perceptivas que lhe permitem sobreviver e adaptar-se ao meio (Martin \& Fabes, 2009). Ao longo dos dois primeiros anos de vida a criança desenvolve um conjunto de competências sensoriais e motoras que lhe permitem ser cada vez mais ativa na interação e comunicação com o ambiente. $\mathrm{O}$ conceito de causalidade (perceber relações causais) e de permanência do objeto (perceber que os objetos continuam a existir quando não estão visíveis) são também desenvolvidos nesta altura (Dehart et al., 2004).

As primeiras palavras surgem por volta dos 12 meses e ao redor dos dois anos a criança atinge o desenvolvimento conceitual necessário para o aperfeiçoamento da linguagem. Paralelamente, a criança também fica mais autônoma no que diz respeito a aspetos básicos como comer, vestir ou tratar da sua higiene (Vialle, Lysaght, \& Verenikina, 2000). Entre os dois e os três anos e meio de idade, a capacidade da criança em comunicar eficazmente torna-se cada vez mais complexa tanto ao nível do vocabulário receptivo como expressivo. No entanto, o vocabulário da criança é muito limitado, vocaliza frases de cerca de duas palavras, e comete erros de subextensão (e.g., chamar chapéu apenas ao seu chapéu, e não a todos os chapéus), de sobre-extensão (e.g., chamar carro a todos os veículos de quatro rodas ou árvore a todas as plantas), entre outros (Dehart et al., 2004).

Nesta fase, também a forma de pensar da criança apresenta ainda algumas características que poderão dificultar a sua capacidade de testemunhar: (a) concreticidade - incapacidade de pensar em conceitos abstratos; (b) egocentrismo - incapacidade de ver uma situação do ponto de vista do outro; (c) centração - incapacidade de explorar todos os aspectos de um estímulo; (d) incapacidade de pensar em transformações - e.g., transformação dos estados físicos da matéria; e (e) irreversibilidade - ausência do conceito de conservação como consequência da centração (Dehart et al., 2004).

No que concerne à memória, a criança já nasce com diversas competências desenvolvidas (Martin \& Fabes, 2009). Esta é capaz de recorrer à sua memória não-declarativa, como a memória procedural. A memória explícita, ou seja, a recordação intencional ou episódica de informação, começa a ser desenvolvida durante o primeiro ano de vida. Por volta dos 13-20 meses as crianças referem-se a episódios passados após vários meses da sua ocorrência (Goodman \& Melinder, 2007). Numa fase inicial da infância, as memórias são codificadas e processadas maioritariamente de forma literal, ou seja, são retidos aspectos exatos e específicos da experiência - traços verbatim. Ao longo do seu desenvolvimento, as crianças começam a ser capazes de extrair o significado 
Paulo, R., Albuquerque, P. B. \& Bull, R. (2015). Entrevista de Crianças e Adolescentes em Contexto Policial e Forense: Uma Perspectiva do Desenvolvimento.

geral das suas experiências - traços gist, desenvolvendo a memória de essência que poderá permitir o armazenamento de informação durante mais tempo (Stein, 2010). Por volta dos dois anos de idade a criança torna-se capaz de relatar episódios passados ainda mais remotos, embora necessite frequentemente da ajuda dos pais, ou de outro adulto (Tulving \& Craik, 2002).

Entre os dois e três anos de idade, juntamente com a aquisição da linguagem, desenvolve-se a memória semântica, relativa a significados e conceitos. De fato, o desenvolvimento da linguagem é muito importante para o desenvolvimento da memória humana. É a linguagem que permite às crianças classificarem suas memórias (e.g., a memória do aniversário) e falar acerca de determinado acontecimento, facilitando a sua memorização. A aquisição da linguagem permite ainda aos pais, ou outras pessoas, direcionar a atenção das crianças para determinado episódio (Stein, 2010).

Em suma, é ainda bastante difícil entrevistar nos contextos forense e policial uma criança na primeira infância, não porque esta não possa reter a informação relativa a um crime, mas sim pela sua dificuldade em relatá-la. Esta dificuldade manifesta-se tanto por aspectos relacionados com a linguagem (e.g., vocabulário reduzido), como pelas questões relativas à memória. Mesmo crianças com dois $\mathrm{e}$ três anos possuem ainda uma capacidade de memória, de reflexão e de comunicação muito limitada. Nos casos em que a criança é a única testemunha e seja considerado útil entrevistá-la, deve-se ter em conta que a informação obtida será provavelmente muito reduzida e, possivelmente, pouco confiável (Hershkowitz et al., 2012).

\section{Periodo Pré-escolar}

A partir dos três anos de idade a capacidade comunicativa da criança torna-se cada vez mais complexa e esta começa a ser capaz de compreender diferentes perspectivas simbólicas e diferenciar a vida mental do mundo real (Vialle et al., 2000). Entre os quatro e os cinco anos de idade, a criança já é capaz de atribuir diferentes estados mentais a si e aos outros, e de prever e explicar o comportamento dos outros com base nos seus respectivos estados mentais. Dos quatro aos seis anos de idade as crianças começam a ponderar a possibilidade de existirem diversos pontos de vista acerca do mesmo objeto e a serem capazes de distinguir a verdade de uma mentira (Papalia et al., 2009). Pode-se ainda observar um desenvolvimento motor e cognitivo intenso, visível através do tipo de jogos e atividades que as crianças executam. Assim, as crianças tornam-se capazes de cooperar com terceiros, começam a estabelecer relações causais, compreender e controlar as suas emoções, bem como falar abertamente sobre elas (Dehart et al., 2004). Por fim, aos cinco anos de idade, as crianças são já capazes de interpretar e responder adequadamente a questões de resposta aberta, como por exemplo, "O que fizeste hoje?" (Hershkowitz et al., 2012).

Durante o período pré-escolar, as crianças recorrem à sua memória episódica de forma cada vez mais complexa.
No entanto, apresentam um declínio mnésico mais acentuado ao longo do tempo. São também pouco competentes no que diz respeito ao uso de mnemônicas e estratégias de recuperação, ou seja, técnicas utilizadas para memorizar ou recuperar informação (Hershkowitz et al., 2012). Assim, quanto maior é o intervalo de retenção, o intervalo entre a ocorrência do episódio e a recordação do mesmo, pior é a qualidade da recordação (Carneiro, 2008).

Durante esse período, as crianças ainda têm dificuldade para manter o material verbal no armazenamento fonológico, por meio da repetição fonológica, o que resulta numa memória de curto prazo menos eficaz (Carneiro, 2008). Estas crianças exibem uma tendência a se fixarem nos acontecimentos centrais do episódio a recordar (e.g., comportamento do criminoso), ignorando os acontecimentos periféricos (e.g., comportamento de outras testemunhas) e centrando-se menos nos pormenores relevantes para a investigação policial (Westcott, Davies, \& Bull, 2002). Nesse período, as crianças apresentam desempenhos elevados em tarefas de reconhecimento, particularmente de localização espacial, mas apresentam baixos desempenhos em tarefas de evocação (Carneiro, 2008). Tal poderá ser explicado pela sua incapacidade em utilizar mnemônicas ou estratégias de recuperação (Westcott et al., 2002). Este aspecto torna-se particularmente problemático, pois crianças mais novas parecem ser particularmente sugestionáveis quando são utilizadas questões ou pistas de recuperação inadequadas (Goodman \& Melinder, 2007) e as tarefas de reconhecimento são mais propícias à inclusão acidental deste tipo de questões ou pistas (Stein, 2010). Por fim, no período pré-escolar as crianças têm dificuldade em monitorizar a fonte das suas memórias, por exemplo, distinguir se recordam certo episódio porque o presenciaram ou porque foi relatado pelos pais (Poole \& Lamb, 1998). Estes fatores poderão traduzir-se na produção de relatos com menor quantidade de informação e de detalhes corretos, e maior quantidade de erros (Goodman \& Melinder, 2007).

Hershkowitz et al. (2012) sugerem que é possível entrevistar no contexto forense e policial uma criança com mais de três anos de idade, pois esta é capaz de interpretar e responder a questões simples. No entanto, poderá ser necessário utilizar pistas de recuperação, baseadas no que a criança disse anteriormente, para direcionar a conversa e obter relatos mais extensos. Não obstante, este tipo de pistas de recuperação deverá ser cuidadosamente utilizado, pois, pistas inadequadas (e.g., pistas sugestivas) poderão aumentar a quantidade de informação incorreta evocada (Lamb et al., 2011). Sem desconsiderar o desenvolvimento acentuado da linguagem no período pré-escolar, o entrevistador não deve superestimar as competências verbais da criança. Este deve assegurar que a criança percebe o seu vocabulário e que ele próprio percebe a criança, pois embora a criança já possua um vocabulário extenso, continua a exibir algumas limitações como dificuldade em articular certos sons (Westcott et al., 2002). A partir dos cinco anos de idade as crianças já são capazes de responder a questões abertas. Assim, o entrevistador deve utilizar principalmente 
este tipo de questionamento pois este é o tipo de questões que produz um maior nível de informação correta (Powell, Hughes-Scholes, Smith, \& Sharman, 2012).

Uma vez que crianças no período pré-escolar, ou mais novas, demonstram dificuldade em manter a atenção num objeto ou tarefa, torna-se vital estar atento ao seu comportamento e perceber quando convém introduzir uma pausa na entrevista. É igualmente importante conduzir a entrevista numa sala acolhedora para a criança, mas que não contenha muitos brinquedos, quadros, desenhos ou outras potenciais distrações (Poole \& Lamb, 1998). Embora estas crianças já sejam capazes de localizar eventos no espaço e no tempo, fazem-no na maioria das vezes de uma forma prática e fazendo referência ao que lhes é familiar (e.g., "Aconteceu lá onde eu como, depois de ver televisão"). Assim, perguntas como "Que horas eram quando ouviste teus pais brigarem?" devem ser substituídas por "O que estavas fazendo quando ouviste teus pais brigando?" (Toeplitz-Winiewska, 2007). Crianças no período pré-escolar são capazes de compreender as intenções dos outros, nomeadamente do entrevistador, preocupando-se em não desapontá-lo. $\mathrm{O}$ entrevistador precisa certificar-se que a criança não responde com o intuito de agradar a alguém (e.g., família) ou ao próprio entrevistador, fornecendo a informação que acha que o adulto pretende ouvir (Hershkowitz et al., 2012). É importante transmitir à criança que poderá afirmar que "não se lembra" sempre que quiser, pois esta é uma resposta tão boa como outra qualquer.

É particularmente importante desenvolver uma boa relação com crianças no período pré-escolar que são testemunhas. Desse modo, obtem-se mais cooperação e se propicia que as testemunhas possam acessar mais facilmente à memória (Fisher \& Geiselman, 1992). Além disso, pode-se conseguir maior adesão da criança ao uso das mnemônicas propostas pelo investigador, pois, como referido anteriormente, crianças no período pré-escolar têm particular dificuldade em utilizar espontaneamente estas mnemônicas. Pode ser interessante incluir o cuidador na entrevista pois a separação da figura de vinculação pode ser extremamente difícil e impedir algumas crianças de prestar qualquer tipo de relato (Saywitz \& Camparo, 1998). No entanto, esta decisão acarreta desvantagens, podendo diminuir a disponibilidade da criança para discutir certos assuntos mais delicados ou constrangedores.

\section{Período Escolar}

A partir dos seis anos de idade, o vocabulário das crianças aumenta consideravelmente, em parte devido a sua entrada no sistema educativo (Vialle et al., 2000). As crianças tornam-se capazes de avaliar comportamentos com base no seu conceito de moralidade, interpretando certos comportamentos como negativos ou inadequados e inibindo-os (Dehart et al., 2004). O desenvolvimento do conceito de moralidade poderá traduzir-se na omissão de detalhes por parte das crianças durante a entrevista. Por exemplo, a criança poderá omitir comportamentos sexuais do agressor por considerá-los constrangedores. Assim, o papel do entrevistador é criar um contexto no qual estas se sintam à vontade para comunicar tais aspectos (Toeplitz-Winiewska, 2007). No período escolar, tal como na adolescência, fatores sociais como a aceitação dos pares e o medo de ser rejeitada têm particular importância. Assim, o entrevistador deve ser particularmente claro ao comunicar à criança que não deve dar uma resposta apenas por achar que essa é a resposta desejada. Deve também avaliar e discutir com a criança qual a sua motivação para testemunhar, pois, por exemplo, esta pode não querer testemunhar por coação dos outros ou medo de ser rejeitada (Powell et al., 2012). Mais uma vez, o estabelecimento de uma boa relação com a testemunha poderá ajudar a ultrapassar estes obstáculos, motivando a criança para testemunhar.

A partir dos sete anos, a capacidade das crianças em realizar repetição espontânea da informação verbal mantendo-a na alça fonológica, traduz-se numa memória de curto prazo mais eficiente (Carneiro, 2008). Entre os sete e os 12 anos de idade, estas crianças exibem maior controle sobre as mnemônicas utilizadas, que passam a utilizar espontaneamente (Gathercole \& Hitch, 1993). Segundo London, Bruck, Poole e Melnyk (2011), é no período escolar que as crianças se tornam capazes de compreender o conceito de sugestionabilidade, sendo, por exemplo, capazes de identificar se o entrevistador utiliza técnicas sugestivas. A evocação livre destas crianças já é equiparável a dos adultos. Assim, a utilização do relato livre e de questões abertas (e.g., "O que aconteceu hoje?") é fundamental de forma a aumentar o número de informações evocadas e diminuir a quantidade de erros cometidos. O entrevistador deve evitar sempre que possível o uso de questões fechadas, particularmente questões sugestivas - "O ladrão tinha uma pistola, certo?” (Goodman \& Melinder, 2007).

\section{Adolescência}

A adolescência é marcada por um conjunto de processos biológicos, como a maturação física e sexual, que resultam em mudanças emocionais e cognitivas (Wright, London, \& Waechter, 2010). O desenvolvimento cognitivo pode superar o desenvolvimento emocional e social, resultando numa maior dificuldade na regulação emocional (Toeplitz-Winiewska, 2007). Assiste-se igualmente ao desenvolvimento da identidade e à procura da independência, em que os pares, e a socialização com estes, são um aspecto crucial com elevada influência na explicação do comportamento individual (Dehart et al., 2004).

No que diz respeito ao funcionamento cognitivo e mnésico dos adolescentes, este é equiparável ao dos adultos (Martin \& Fabes, 2009), podendo ser entrevistados como tal no que diz respeito às suas capacidades intelectuais (e.g., complexidade das questões). No entanto, é importante considerar os fatores emocionais e sociais anteriormente descritos na construção e execução da entrevista policial ou forense, tendo em vista que o medo da pressão pública, do ofensor, e da exclusão social resultante do processo judicial pode influenciar a motivação da testemunha para relatar o crime (Toeplitz-Winiewska, 2007). Wright et al. (2010) 
Paulo, R., Albuquerque, P. B. \& Bull, R. (2015). Entrevista de Crianças e Adolescentes em Contexto Policial e Forense: Uma Perspectiva do Desenvolvimento.

sugerem até que a ansiedade social nos adolescentes está associada a uma maior vulnerabilidade à sugestionabilidade. Mais uma vez, estabelecer uma boa relação com a testemunha é fundamental para que esta se sinta motivada para testemunhar e confortável perante a entrevista. Desse modo, pode-se facilitar a regulação dos estados emocionais da testemunha, que poderão afetar negativamente o sucesso da entrevista, uma vez que o medo e a ansiedade conduzem à evocação de menos detalhes (Walsh \& Bull, 2011). Este procedimento poderá ainda prevenir que os adolescentes exibam comportamentos de confrontação face ao entrevistador, típicos deste período de desenvolvimento como resultado da procura de independência e autonomia (Westcott et al., 2002).

Previamente caracterizou-se a memória ao longo das diversas etapas do desenvolvimento humano, definindo algumas orientações a serem seguidas e preocupações a considerar no que diz respeito à construção e condução de entrevistas policiais e forenses. A seguir, serão abordados alguns aspectos que devem ser considerados quando entrevistam-se crianças e adolescentes, independentemente da etapa de desenvolvimento em que se inserem.

\section{Como Entrevistar Crianças e Adolescentes? - Aspetos Gerais}

Uma das principais preocupações na entrevista de crianças ou adolescentes é avaliar adequadamente a fase desenvolvimental em que a testemunha se encontra (Saywitz \& Camparo, 1998). É essencial analisar a história do desenvolvimento da criança, recorrendo não só ao relato e à avaliação psicológica da própria testemunha, mas também à análise dos relatos dos pais e educadores ou outros registros existentes (e.g., médicos, escolares, etc.). O entrevistador deve conduzir a entrevista de acordo com a fase de desenvolvimento da criança (Hershkowitz et al., 2012). Uma criança que não aprendeu a contar, por exemplo, não pode ser questionada acerca de quantas vezes o agressor ameaçou a vítima. Precisa considerar outros aspectos igualmente importantes para o sucesso da entrevista, por exemplo, recolher informação sobre o caso, definir os objetivos da entrevista, avaliar qual o melhor momento para entrevistar a criança, etc. (Lamb et al., 2011). Deve ainda interpretar as respostas da criança de acordo com a avaliação efetuada. Por exemplo, é frequente uma criança substituir termos não familiares por outros mais familiares, como verbalizar cola em vez de sémen. Não obstante, este tipo de interpretações tem de ser confirmado e discutido com a criança ao longo da entrevista, e não apenas deduzido pelo entrevistador (Saywitz \& Camparo, 1998).

Outra preocupação a considerar em qualquer entrevista policial ou forense é a utilização de linguagem simples, sem conceitos complexos como termos legais, que possam dificultar a compreensão das questões (Fisher \& Geiselman, 1992). O entrevistador deve abordar um tópico de cada vez, utilizar a voz ativa, utilizar frases simples e evitar frases ambíguas ou formuladas na forma negativa (Saywitz \& Camparo, 1998). Estes fatores têm particular importância quando lidamos com crianças, pois poderão ter um vocabulário reduzido e ser incapazes de monitorar a sua própria compreensão (Lamb et al., 2011). Utilizar a mesma terminologia que o entrevistado é aconselhado, evitando problemas de interpretação, por exemplo, utilizar "velho" em vez de "idoso" caso a criança o faça. No entanto, é importante que o entrevistador não utilize uma linguagem que possa ser vista como inadequada pelo avaliado, como usar fala infantilizada (Poole \& Lamb, 1998).

A pertinência de submeter a criança ou adolescente a mais do que uma entrevista tem sido alvo de alguma discussão (Poole \& Lamb, 1998). Esta prática parece ser problemática caso alguma das entrevistas realizadas seja inadequada, por exemplo, contenha questões sugestivas. Se a primeira entrevista realizada contiver questões sugestivas, a memória da criança poderá ser distorcida e os erros cometidos nesta entrevista poderão manter-se em entrevistas posteriores (Lapaglia, Wilford, Rivard, Chan, $\&$ Fisher, 2013). Caso todas as entrevistas sejam adequadas, este procedimento poderá ser vantajoso, aumentando a quantidade de informação evocada, particularmente em crianças, pois estas frequentemente omitem informação numa primeira entrevista (Poole \& Lamb, 1998). Inconsistências entre os relatos não põem necessariamente em causa a sua credibilidade. É habitual, particularmente em crianças, que as suas competências, constantemente em evolução, se desenvolvam ao longo deste processo e que nova informação seja evocada ao longo das sucessivas tentativas de recordação (Peterson, 2012). Por fim, no caso de testemunhas que viveram situações potencialmente traumáticas ou dolorosas, o entrevistador deve ponderar se a condução de múltiplas entrevistas será uma forma de revitimação para a testemunha (Stein, 2010).

Convém realçar que a questão da sugestionabilidade não surge apenas na condução de entrevistas repetidas. Basta uma entrevista, pergunta, procedimento, estereótipo ou postura inadequada para influenciar o discurso da criança (Goodman \& Melinder, 2007). Perguntas sugestivas variam desde instruções diretas para imaginar o evento (e.g., "caso o teu avô te tocasse, onde seria?") até ao questionamento de caráter repetido e exaustivo (e.g., "vou te perguntar outra vez, tens certeza que não te tocaram!?”). A sugestionabilidade pode igualmente ser influenciada por fatores sociais, cognitivos, motivacionais e diferenças individuais das próprias crianças (Lamb et al., 2011; Stein, 2010). O contato que a criança mantém com os pais ou outras testemunhas entre o período em que testemunhou o crime e o período em que é entrevistada poderá também influenciar a narrativa da criança (Principe \& Schindewolf, 2012). Desta forma, o contato entre testemunhas deve ser evitado e cada uma delas entrevistada o mais rapidamente possível (McGuire, London, \& Wright, 2011).

Recorrer ao desenho durante a entrevista é uma prática que também tem gerado controvérsia (Hiltz \& Bauer, 2003). O recurso ao desenho pode ser utilizado de diversas 
formas e para diferentes fins. Pedir à criança no início da entrevista, com o intuito de diminuir a sua ansiedade e criar uma boa relação, para que desenhe algo é adequado. Solicitar à criança que desenhe um esquema do local do crime poderá ser vantajoso para auxiliar a evocação verbal. Este procedimento foi incluído em algumas versões da Entrevista Cognitiva Melhorada, que iremos descrever mais à frente, e, embora ainda não tenha sido aplicado a crianças, mostrou ser vantajoso para adultos (Dando et al., 2008). Não obstante, utilizar desenhos como forma de auxiliar a evocação verbal exige cuidado da parte do entrevistador. É preciso assegurar que não são utilizados comentários sugestivos (“é uma arma, não é?"), e que os desenhos não estão interferindo na concentração da criança na tarefa de evocação. Crianças mais novas demonstram dificuldade em concentrar-se em várias tarefas simultâneas (Poole \& Bruck, 2012). Por fim, qualquer tentativa do entrevistador de interpretar clinicamente os desenhos da criança, como interpretar uma mão proeminente como sinal que esta foi agredida, é inadequada. A inexistência de regras de cotação/ interpretação válidas e universais para este tipo de interpretações torna esta prática demasiado subjetiva (Hiltz \& Bauer, 2003).

Frequentemente, alguns entrevistadores utilizam outros auxiliares de evocação como, por exemplo, as bonecas anatomicamente corretas. Estas são bonecas/os com algumas das características sexuais dos humanos, tipicamente utilizadas nas avaliações forenses, particularmente em casos de abuso sexual. Utilizando este material, é pedido à criança que, por exemplo, indique o local onde foi agredida ou tocada de forma sexual. Práticas semelhantes podem ser conduzidas com desenhos do corpo humano. Esta técnica acarreta vários problemas (Stein, 2010). Em primeiro lugar, não existem normas claras para o uso deste material e interpretação das respostas obtidas. Em segundo lugar, as crianças poderão ter dificuldades em visualizar a/o boneca/o ou desenho como uma representação de si, evocando informação relativa a uma personagem imaginária que elas criam para a/o boneca/o (Poole \& Bruck, 2012). Finalmente, a investigação não apoia que o uso desta técnica produza mais informação correta do que uma tarefa de evocação livre sem o uso de material auxiliar (Poole \& Lamb, 1998). Em suma, o uso deste tipo de material deve ser substituído, por exemplo, pelo uso de mnemônicas, pois este tipo de técnicas tem mostrado ser bastante mais eficaz.

A última prática polêmica que iremos abordar é a tentativa do entrevistador de avaliar a credibilidade do relato. Para tal, são tipicamente utilizadas algumas estratégias, como apresentar à criança um conjunto de declarações, pedindo-lhe para as classificar como verdadeiras ou falsas, avaliando a capacidade da criança em diferenciar a verdade da mentira. Outra estratégia comum é encarar o nível de detalhe do discurso como um indicador de credibilidade, assumindo que a criança seria incapaz de fabricar um discurso elaborado. Na verdade, muitos outros factores influenciam o nível de detalhe do relato. Por exemplo, as crianças parecem ser capazes de evocar mais detalhes relativos a histórias de valência negativa do que a histórias de valência positiva, embora a exatidão da memória seja prejudicada no primeiro caso (Feix, 2008). Independentemente da estratégia utilizada, a investigação sugere que os profissionais são incapazes de distinguir relatos verdadeiros de falsos (Klemfuss \& Ceci, 2012; Zajac, Garry, London, Goodyear-Smith, \& Hayne, 2013).

Por fim, existe um conjunto de diretrizes que o entrevistador deve seguir, pois, embora importantes para qualquer testemunha, são particularmente relevantes para crianças e adolescentes:

1. Explicar à testemunha qual a razão porque foi chamada, indicando ainda pormenorizadamente o que irá acontecer ao longo do processo de entrevista e/ ou processo judicial. As crianças têm, por vezes, uma compreensão muito limitada sobre os processos judiciais a que são sujeitas, bem como estratégias menos desenvolvidas para lidar com a ansiedade e incerteza proveniente destes processos (Westcott et al., 2002);

2. Estabelecer uma boa relação com a testemunha, pelas razões anteriormente expostas;

3. Pedir à criança que forneça o máximo de informação e detalhe possível nas suas descrições posto que foi ela quem presenciou o crime e possui informação que o entrevistador desconhece;

4. Informar a testemunha para não tentar adivinhar ou supor nada;

5. Indicar à testemunha que, embora o exercício de recordar informação seja naturalmente exigente, o entrevistador estará presente para a ajudar; e,

6. Pedir à criança um relato inicial onde o entrevistador intervém o menos possível (Fisher \& Geiselman, 1992; Lamb et al., 2011; Saywitz \& Camparo, 1998).

Assim, e uma vez que todos os procedimentos descritos no parágrafo anterior são parte constituinte da Entrevista Cognitiva, ou Entrevista Cognitiva Melhorada na sua forma atual (Fisher \& Geiselman, 1992) sendo até alguns procedimentos originários desta entrevista, este modelo de entrevista será brevemente descrito. A sua utilidade para a entrevista policial e forense de crianças e adolescentes será realçada.

\section{Entrevista Cognitiva Melhorada}

Baseando-se na investigação acerca da memória humana (Tulving \& Thomson, 1973) e com o objetivo de obter o máximo de informação possível, Geiselman et al. (1984) criaram a Entrevista Cognitiva. Atualmente é considerada uma das técnicas mais eficazes para melhorar o relato de uma testemunha.Vários estudos têm mostrado que esta técnica aumenta a quantidade de informação evocada pelas testemunhas sem comprometer a exatidão (Milne, Sharman, Powell, \& Mead, 2013). Esta entrevista mostrou ser eficaz em diferentes países (EUA, Reino Unido, Alemanha ou Brasil), com diferentes tipos de testemunhas 
Paulo, R., Albuquerque, P. B. \& Bull, R. (2015). Entrevista de Crianças e Adolescentes em Contexto Policial e Forense: Uma Perspectiva do Desenvolvimento.

(crianças, adultos ou idosos), diferentes tipos de episódios a recordar (e.g., crimes, acidentes ou chamadas telefónicas) e diferentes intervalos de tempo entre o episódio a recordar e a sua evocação (desde poucos minutos a vários dias), tanto em laboratório como em estudos de campo (Paulo, Albuquerque, \& Bull, 2013). Quando publicada pela primeira vez, a Entrevista Cognitiva incluía quatro fases ou técnicas: restabelecimento do contexto; contar tudo; mudança de ordem; e a mudança de perspectiva (Geiselman et al., 1984).

Em primeiro lugar, o restabelecimento do contexto baseia-se na ideia de que a recuperação de informação é superior quando o contexto original onde o episódio ocorreu é recriado durante a entrevista (Tulving \& Thomson, 1973). Assim, o entrevistador pede à testemunha que recrie mentalmente a cena do crime, bem como o seu estado psicológico, cognitivo e emocional no momento. Em seguida, a técnica de contar tudo consiste em pedir à testemunha que conte tudo o que se recorda sobre o crime, mesmo os detalhes que lhe pareçam triviais. A técnica de mudança de ordem consiste em pedir à testemunha que conte o acontecimento seguindo uma ordem cronológica diferente, usualmente começando pelo final. Esta técnica pretende aumentar a quantidade de informação evocada, utilizando uma estratégia de recuperação diferente da inicial. Por fim, a técnica de mudança de perspectiva consiste em pedir à testemunha que recorde o acontecimento através de uma perspectiva diferente. Por exemplo, se a testemunha está manifestamente ansiosa, poderemos pedir-lhe que recorde o episódio por meio de uma perspectiva mais tranquila.

Passados alguns anos, Fisher e Geiselman (1992) propuseram uma nova versão desta entrevista incluindo um conjunto de componentes sociais e comunicativos: (a) fazer perguntas compatíveis com o relato da testemunha; (b) criar um bom clima emocional com esta (e.g., mostrando disponibilidade para ajudar); (c) transferir o controle da entrevista para a testemunha (e.g., controle para afirmar que não recorda); e (d) criar imagens mentais para detalhes específicos (e.g., imaginar a arma do assaltante).

Particularmente interessante para o presente artigo é o fato de existirem vários estudos que sugerem que esta entrevista é peculiarmente eficaz com crianças das mais diversas faixas etárias (Gentle et al., 2013; Holliday \& Albon, 2004; Verkampt \& Ginet, 2010). Adicionalmente, este modelo de entrevista focaliza um conjunto de aspectos que, tal como abordado ao longo do artigo, são essenciais quando se entrevista crianças e adolescentes no contexto policial e forense. Por exemplo, pedir ao entrevistado que utilize mnemônicas como o restabelecimento do contexto e uso de imagens mentais é particularmente importante com crianças no período pré-escolar. Por um lado, a sua memória está fortemente associada ao contexto, e por outro estas são incapazes de utilizar tais mnemônicas espontaneamente (Gathercole \& Hitch, 1993). Estabelecer uma boa relação com a testemunha é também fundamental pelas razões já abordadas. Além disso, uma vez que esta relação começa usualmente por ser estabelecida no início da entrevista abordando com a testemunha temas rotineiros, o entrevistador poderá utilizar este processo para iniciar a sua avaliação das competências cognitivas e linguísticas da criança. Poderá ainda avaliar qual o ritmo a manter durante a entrevista e quais os procedimentos a utilizar (Lamb et al., 2011). Pedir à testemunha para "contar tudo" num relato inicial em que o entrevistador intervém o menos possível, é também particularmente importante com crianças e adolescentes. Assim, é evitado que o entrevistador influencie o seu relato e contrariada a tendência das crianças mais novas em emitir relatos telegráficos (Poole \& Lamb, 1998). Não obstante, estes autores sugerem que certas mnemônicas devem ser utilizadas com particular cuidado quando aplicadas a crianças. Ao realizar o restabelecimento do contexto, o entrevistador deve certificar-se que a criança compreendeu corretamente a mnemônica. Algumas crianças poderão interpretar esta mnemônica como um exercício de imaginação, onde lhes é pedido para fabricar detalhes. Assim, mnemônicas como esta, a mudança de ordem ou a mudança de perspectiva podem ser demasiado complexas para crianças mais novas (Stein, 2010).

A Entrevista Cognitiva deve ser utilizada de forma flexível, sendo legítimo o entrevistador excluir ou incluir diferentes procedimentos (Fisher \& Geiselman, 1992). Por exemplo, a inclusão de um relato inicial de treino, como o relato de um episódio do dia a dia, poderá facilitar a compreensão das crianças mais novas relativamente às instruções propostas (Lamb et al., 2011). Assim, adaptar este (ou outro) modelo de entrevista com base na avaliação do desenvolvimento da testemunha é um procedimento essencial. Para tal, o entrevistador deverá ter em conta todas as diretrizes e considerações abordadas ao longo do presente artigo bem como formação na aplicação deste modelo de entrevista.

\section{Conclusão}

Em suma, conclui-se que é fundamental avaliar a fase de desenvolvimento em que a testemunha se insere e conhecer as características de cada uma destas fases. Só assim é possível compreender quais as competências da testemunha e conduzir uma entrevista adequada. É igualmente importante preparar e adaptar a entrevista, bem como interpretar cuidadosamente as respostas da testemunha, de acordo com esta avaliação. Ao longo deste artigo foram abordados alguns aspectos globais a serem considerados para a realização de uma boa entrevista com crianças e adolescentes. Referimos ainda considerações a ter em mente para cada etapa de desenvolvimento, como utilizar pistas de recuperação baseadas no relato da testemunha, para algumas crianças no período pré-escolar. Por fim, conclui-se ainda que a Entrevista Cognitiva Melhorada engloba um conjunto de características que a tornam particularmente adequada para crianças e adolescentes, tal como a investigação corrobora (Gentle et al., 2013). Não obstante, obter formação na área da entrevista de testemunhas e adaptar a entrevista policial ou forense conforme as 
características da investigação e da testemunha será sempre fundamental. Futuras investigações que analisem a forma e eficácia com que os diversos grupos de profissionais, sejam estes agentes policiais, psicólogos forenses, ou outros peritos, avaliam a fase de desenvolvimento da testemunha e adaptam e realizam a entrevista investigativa de acordo com esta avaliação são imprescindiveis.

\section{Referências}

Almeida, A., \& Cunha, G. (2003). Representações sociais do desenvolvimento humano. Psicologia: Reflexão e Crítica, 16, 147-155. doi:10.1590/S0102-79722003000100015

Brainerd, C. J., \& Reyna, V. F. (2012). Reliability of children's testimony in the era of developmental reversals. Developmental Review, 32, 224-267. doi:10.1016/j.dr.2012.06.008

Carneiro, P. (2008). Desenvolvimento da memória na criança: O que muda com a idade? Psicologia: Reflexão e Crítica, 21, 51-59. doi:10.1590/S0102-79722008000100007

Dando, C., Wilcock, R., Milne, R., \& Henry, L. (2008). A modified cognitive interview procedure for frontline police investigators. Applied Cognitive Psychology, 23, 698-716. doi:10.1002/acp.1501

Dehart, B. G., Sroufe, A. L., \& Cooper, R. G. (2004). Child development: Its nature and course ( $5^{\text {th }}$ ed.). New York: McGraw-Hill.

Feix, L. F. (2008). Efeito da emoção na memória de crianças (Tese de doutorado não publicada, Pontifícia Universidade Católica do Rio Grande do Sul, Porto Alegre, RS Brasil).

Fisher, R. P., \& Geiselman, R. E. (1992). Memory-enhancing techniques for investigative interviewing: The cognitive interview. Springfield, IL: Charles C. Thomas.

Gathercole, S. E., \& Hitch, G. J. (1993). Developmental changes in short-term memory: A revised working memory perspective. In A. Collins, S. E. Gathercole, M. A. Conway, \& P. E. Morris (Eds.), Theories of memory (pp. 189-209). Hove, UK: Erlbaum.

Geiselman, R. E., Fisher, R. P., Firstenberg, I., Hutton, L., Sullivan, S. J., Avetissian, I. V., \& Prosk, A. L. (1984). Enhancement of eyewitness memory: An empirical evaluation of the cognitive interview. Journal of Police and Science Administration, 12, 74-80.

Gentle, M., Milne, R., Powell, M. B., \& Sharman, S. J. (2013). Does the cognitive interview promote the coherence of narrative accounts in children with and without an intellectual disability? International Journal of Disability, Development and Education, 60, 30-43. doi:10.1080/1034912X.2013.757138

Goodman, G. S., \& Melinder, A. (2007). Child witness research and forensic interviews of young children: A review. Criminal and Criminological Psychology, 12, 1-19. doi:10.1348/135532506X156620

Hershkowitz, I., Lamb, M. E., Orbach, Y., Katz, C., \& Horowitz, D. (2012). The development of communicative and narrative skills among preschoolers: Lessons from forensic interviews about child abuse. Child Development, 83, 611-622. doi:10.1111/j.1467-8624.2011.01704.x

Hiltz, B., \& Bauer, G. (2003). Drawings in forensic interviews of children. APRI Update, 16, 1-2.

Holliday, R., \& Albon, A. (2004). Minimising misinformation effects in young children with cognitive interview mnemonics. Applied Cognitive Psychology, 18, 263-281. doi:10.1002/ acp. 973
Klemfuss, J. Z., \& Ceci, S. J. (2012). Legal and psychological perspectives on children's competence to testify in court. Developmental Review, 32, 268-286. doi:10.1016/j.dr.2012.06.005

Lamb, M. E., La Rooy, D. J., Malloy, L. C., \& Katz, C. (2011). Children's testimony: A handbook of psychological research and forensic practice ( $2^{\text {nd }}$ ed.). London: Wiley-Blackwell. doi:10.1002/9781119998495

Lapaglia, J. A., Wilford, M. M., Rivard, J. R., Chan, J. S. K., \& Fisher, R. P. (2013). Misleading suggestions can alter later memory reports even following a cognitive interview. Applied Cognitive Psychology, 28, 1-9. doi:10.102/acp.2950

Linhares, M., Chimello, J., Bordin, M., Carvalho, A., \& Martinez, F. (2005). Desenvolvimento psicológico na fase escolar de crianças nascidas pré-termo em comparação com crianças nascidas a termo. Psicologia: Reflexão e Crítica, 18, 109-117. doi: 10.1590/S1413-73722005000200010

London, K., Bruck, M., Poole, D. A., \& Melnyk, L. (2011). The development of metasuggestibily in children. Applied Cognitive Psychology, 25, 146-155. doi:10.1002/acp.1653

Lordelo, E., Chalhub, A., Guirra, G., \& Carvalho, C. (2007). Contexto e desenvolvimento cognitivo: Frequência à creche e evolução do desenvolvimento mental. Psicologia: Reflexão e Crítica, 20, 324-334. doi:10.1590/S0102-79722007000200019

Martin, C. L., \& Fabes, R. (2009). Discovering child development ( $2^{\text {nd }}$ ed.). Boston, MA: Houghton Mifflin Harcourt.

McGuire, K., London, K., \& Wright, D. B. (2011). Peer influence on event reports among adolescents and young adults Memory, 19, 674-683. doi:10.1080/09658211.2011.602086

Milne, R., Sharman, S. J., Powell, M. B., \& Mead, S. (2013). Assessing the effectiveness of the cognitive interview for children with severe intellectual disabilities. International Journal of Disability, Development and Education, 60, 18-29. doi:10.1080/1034912X.2013.757137

Papalia, D. E., Olds, S. W., \& Feldman, R. D. (2009). O mundo da criança-Da infância à adolescência (11. ed.). São Paulo, SP: McGraw-Hill Interamericana.

Paulo, R. M., Albuquerque, P. B., \& Bull, R. (2013). The enhanced cognitive interview: Towards a better use and understanding of this procedure. International Journal of Police Science \& Management, 15, 190-199. doi:10.1350/ ijps.2013.15.3.311

Peterson, C. (2012). Children's autobiographical memories across the years: Forensic implications of childhood amnesia and eyewitness memory for stressful events. Developmental Review, 32, 287-306. doi:10.1016/j.dr.2012.06.002

Poole, D. A., \& Bruck, M. (2012). Divining testimony? The impact of interviewing props on children's reports of touching. Developmental Review, 32, 165-180. doi:10.1016/j. dr.2012.06.007

Poole, D. A., \& Lamb, M. E. (1998). Investigative interviews of children: A guide for helping professionals. Washington, DC: American Psychology Association.

Powell, M. B., Hughes-Scholes, C. H., Smith, R, \& Sharman, S. J. (2012).The relationship between investigative interviewing experience and open-ended question usage. Police Practice and Research: An International Journal, 10, 61-73. doi:10.1 080/15614263.2012.704170

Principe, G. F., \& Schindewolf, E. (2012). Natural conversations as a source of false memories in children: Implications for the testimony of young witnesses. Developmental Review, 32, 205-223. doi:10.1016/j.dr.2012.06.003 
Paulo, R., Albuquerque, P. B. \& Bull, R. (2015). Entrevista de Crianças e Adolescentes em Contexto Policial e Forense: Uma Perspectiva do Desenvolvimento.

Saywitz, K., \& Camparo, L. (1998). Interviewing child witnesses: A developmental perspective. Child Abuse \& Neglect, 22, 825-843.

Stein, L. M. (2010). Falsas memórias: Fundamentos científicos e as suas aplicações clínicas e jurídicas. Porto Alegre, RS: Artmed.

Toeplitz-Winiewska, M. (2007). Development stages and methods of interviewing children. Retrieved from http://www. canee.net/files/Development $\% 20$ Stages $\% 20$ a nd\%20Me thods $\% 20$ of $\% 20$ Interviewing $\% 20$ Children.pdf -

Tulving, E., \& Craik, F. I. M. (2002). The Oxford handbook of memory. New York: Oxford University Press. doi:10.1002/ acp. 822

Tulving, E., \& Thomson, D. (1973). Encoding specificity and retrieval processes in episodic memory. Psychological Review, 80, 352-373.

Verkampt, F., \& Ginet, M. (2010). Variations of the cognitive interview: Which one is the most effective in enhancing children's testimonies? Applied Cognitive Psychology, 24, 1279-1296. doi:10.1002/acp.1631

Vialle, W., Lysaght, P., \& Verenikina, I. (2000). Handbook on child development. Katoomba, Australia: Social Science Press.

Walsh, D., \& Bull, R. (2011). Examining rapport in investigative interviews with suspects: Does its building and maintenance work? Journal of Police and Criminal Psychology, 27, 73-84. doi:10.1007/s11896-011-9087-x

Westcott, H. L., Davies, G. M., \& Bull, R. (2002). Children's testimony: A handbook of psychological research and forensic practice. London: Wiley. doi:10.1002/9780470713679

Wright, D. B., London, K., \& Waechter, M. (2010). Social anxiety moderates memory conformity in adolescents. Applied Cognitive Psychology, 24, 1034-1045. doi:10.1002/acp.1604

Zajac, R., Garry, M., London, K., Goodyear-Smith, F., \& Hayne, H. (2013). Misconceptions about childhood sexual abuse and child witnesses: Implications for psychological experts in the courtroom. Memory, 21, 608-617. doi:10.1080/09658 211.2013.778287 